\title{
Prognostic Factors for Survival of Colorectal Adenocarcinoma Patients in Uganda
}

\author{
Richard Wismayer ${ }^{1-3}$, Julius Kiwanuka ${ }^{4}$, Henry Wabinga ${ }^{3}$, Michael Odida ${ }^{3,5}$ \\ 'Department of Surgery, Masaka Regional Referral Hospital, Masaka, Uganda; ${ }^{2}$ Department of Surgery, Faculty of Health Sciences, Habib Medical \\ School, IUIU University, Kampala, Uganda; ${ }^{3}$ Department of Pathology, School of Biomedical Sciences, College of Health Sciences, Makerere University, \\ Kampala, Uganda; ${ }^{4}$ Department of Epidemiology and Biostatistics, School of Public Health, College of Health Sciences, Makerere University, Kampala, \\ Uganda; ${ }^{5}$ Department of Pathology, Faculty of Medicine, Gulu University, Gulu, Uganda
}

Correspondence: Richard Wismayer, Email richardwismayer@chs.mak.ac.ug; richardwismayer@rcsi.ie

Background: In Uganda, similar to other countries in East Africa, the incidence of colorectal cancer (CRC) has been steadily increasing. This increase in incidence is accompanied by a poor prognosis. There is limited knowledge on factors responsible for the poor outcome of patients with CRC in Uganda. Cancer survival analysis is one way of determining some of these prognostic factors. The aim of this study was to determine prognostic factors associated with CRC survival in Ugandan patients.

Methods: This was a retroprospective cohort study involving patients with linked data in the Kampala cancer registry and medical records from hospitals in Uganda. Participants with a diagnosis of colorectal adenocarcinoma between 1 st January 2008 and 31 st December 2018 were included. Variables included patients' demographic data, grade, stage and location of CRC, data on whether a patient was operated on, type of operation, treatment modalities and date of diagnosis. Our outcome variable was time to death after diagnosis. We computed and compared survival using the Log rank test and used Cox proportional hazards regression to determine factors associated with survival.

Results: A total of 247 patients were included in the study with a mean (SD) age of 53.3 (15.7) years and a female: male ratio of 1.14:1. The proportions of patients surviving at 1,2 and 3 years were $65.2 \%$ (95\% CI: 58.8-70.9), 42.0\% (95\% CI:35.6-48.3) and $33.3 \%$ (95\% CI:27.3-39.4) respectively. In multivariate analysis, factors associated with increased mortality included clinical stage II $(\mathrm{aHR}=2.44,95 \% \mathrm{CI}: 1.10-5.41, \mathrm{p}=0.028)$, stage III $(\mathrm{aHR}=2.65,95 \% \mathrm{CI}: 1.31-5.39, \mathrm{p}=0.007)$ and stage IV $(\mathrm{aHR}=5.47,95 \% \mathrm{CI}$ : $2.40-12.48, \mathrm{p}<0.001)$. Curative surgery alone $(\mathrm{aHR}=0.63,95 \% \mathrm{CI}: 0.39-1.01, \mathrm{p}=0.057)$ and curative surgery with chemotherapy $(\mathrm{aHR}=0.53,95 \% \mathrm{CI}: 0.32-0.88, \mathrm{p}=0.015)$ were associated with a better survival.

Conclusion: The survival rate among CRC patients in Uganda is low. Advanced stage CRC accelerates mortality, while surgery alone or in combination with chemotherapy improves survival. Implementation of national screening programmes for early diagnosis of CRC and increasing surgery and oncology infrastructure is recommended to improve the CRC survival rate in the Ugandan population.

Keywords: colorectal cancer, mortality, overall survival, Uganda

\section{Introduction}

Globally, colorectal cancer (CRC) is the second most common cause of cancer-related mortality and there are large differences reported in survival. ${ }^{1,2}$ In Sub-Saharan Africa, the CRC survival rate has been found to be less than $8 \%$ in Gambia, $16 \%$ in Ghana and less than $30 \%$ in Harare, Zimbabwe, and all of these countries are characterized by poorly developed health care infrastructure and limited availability and accessibility to curative treatments for most patients. ${ }^{3}$ This contrasts with the $60 \%$ survival rate in South Korea, which shows a large variation in CRC survival between different parts of the world. ${ }^{3}$ Effective treatment and early diagnosis have been shown in several studies to reduce CRC mortality. ${ }^{4}$ Compared to developed countries, in the UK and USA, CRC patients in Uganda mainly present in late stages with symptoms of pain, hematochezia and/or large bowel obstruction. These findings are similar to those found in other East African countries. 5,6 
This may be due to the lack of understanding of the common symptoms and signs of CRC among the population, lack of access to colonoscopy to make an early diagnosis and a lack of national screening programmes. ${ }^{7}$ Over the last three decades, a decline in the mortality and incidence of CRC has been observed with the implementation of universal screening in Europe and the United States. ${ }^{8}$ Screening the population through colonoscopy has also been found by mathematical modeling to be a highly cost-effective way to combat CRC in Sub-Saharan Africa. ${ }^{9}$ The early diagnosis results in curative treatment at an early stage leading to a reduction in mortality from CRC and an improvement in survival. ${ }^{10,11}$

Lack of access to surgical treatment, chemotherapy and radiotherapy together with a lack of screening and hence an early diagnosis may be some of the reasons for the differences reported in CRC survival. However many of these differences in survival are not entirely understood. ${ }^{17}$

In East Africa and particularly in Uganda, the relationship of treatment in CRC patients to survival outcome remains unknown. A good indicator to detect the effectiveness of CRC treatment and early diagnosis in a population is through the analyses of cancer survival. The objective of this study was to determine the prognostic factors related to the survival of CRC patients in Uganda. Knowledge of these prognostic factors will guide planning treatment and predicting the outcome of CRC patients in the population.

\section{Methodology}

\section{Study Design \& Setting}

This was a retroprospective cohort study conducted on colorectal adenocarcinoma participants with data linked to the Kampala Cancer Registry and/or data from medical records in Masaka Regional Referral Hospital, Mulago National Referral Hospital, Uganda Martyrs' Hospital Lubaga, Mengo Hospital and Hospice Africa Uganda. Mulago Hospital is the National Referral Hospital and the largest hospital dealing with specialised care in the country. Hospice Africa Uganda provides palliative care for cancer patients in Uganda. All the health facilities that participated in this study are located in central Uganda and receive patients from all regions of Uganda.

\section{Follow Up of Study Participants}

A follow-up period of three (3) years for each study participant was imposed. A patient's follow-up began at the date of CRC diagnosis [time zero $\left(\mathrm{t}_{0}\right)$ ] and continued up to the occurrence of:- (i) death, (ii) loss to follow-up or (iii) censoring at the end of three years. Both passive and active follow-up methods were employed if necessary. The data regarding vital status were obtained partly from the Kampala cancer registry and partly from clinical case files. Active contact tracing was carried out in different regions of Uganda, if necessary, by research assistants for those participants who fell outside the catchment area of the Kampala cancer registry.

For participants in which information on vital status at the closing date was not available, telephone calls or home visits were carried out. For each participant, vital status was achieved at the closing date to achieve complete follow-up. A flow diagram illustrating the procedure used for the selection of colorectal adenocarcinoma case participants is shown in Figure 1.

\section{Study Population and Selection of Participants}

The study population included patients with a clinical case file at any of the participating health facilities. Participants with histologically confirmed colorectal adenocarcinoma linked to data in the Kampala cancer registry and/or clinical case files in the participating health facilities during the period 1st January 2008 to 31st December 2018 were included in this study. Patients were excluded if their clinical file missed demographic data, had no clinical data or had multiple cancers other than colorectal adenocarcinoma.

\section{Sample Size}

Based on a study by Band et al, 2018 the 3 -year survival was $75 \%{ }^{12}$. Given the absence of data on Uganda, we used this study to estimate the sample size based on a hazard ratio of 2.0 comparing surgery to no surgery for CRC. A $10 \%$ loss to 


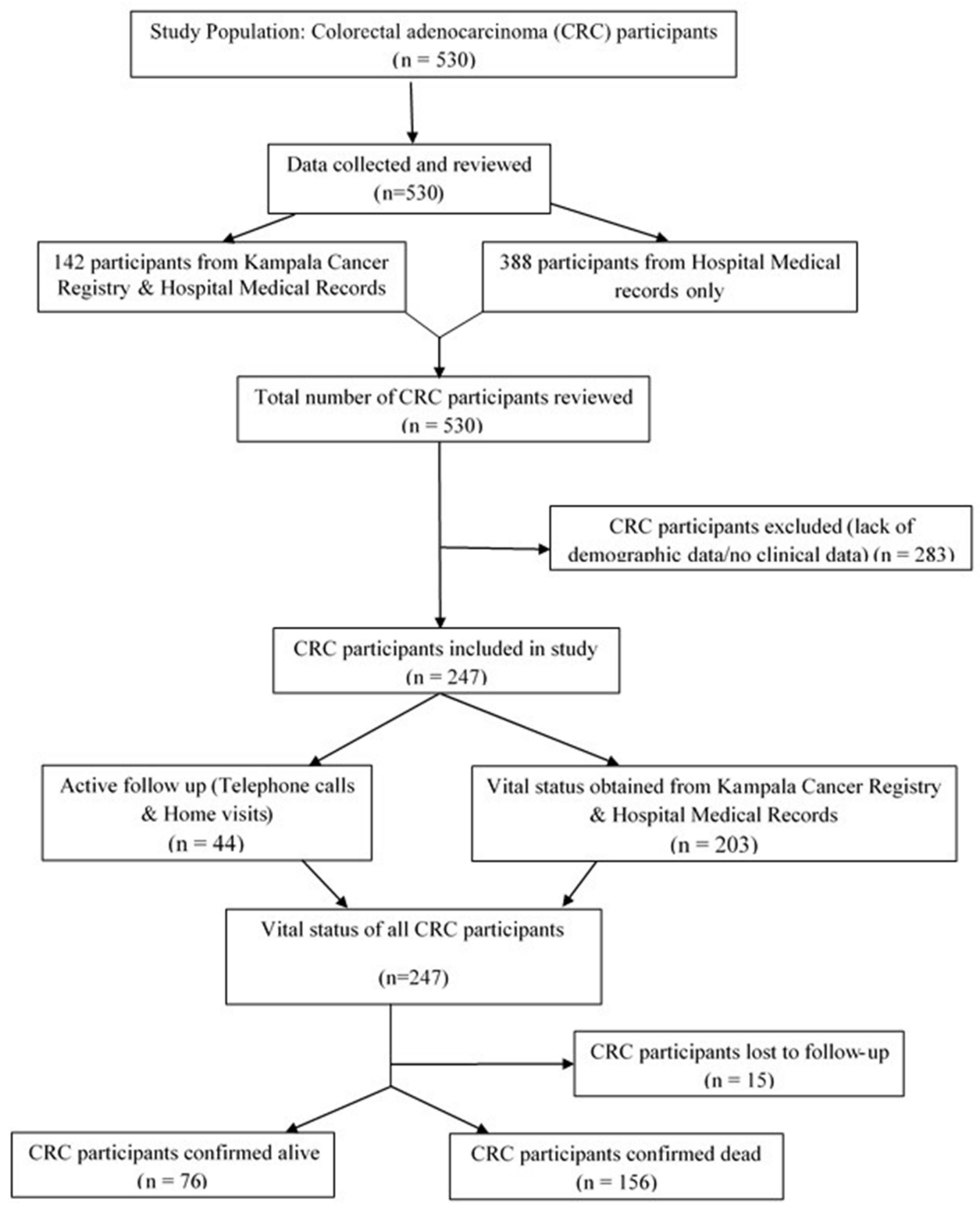

Figure I Colorectal cancer patients' selection flow chart for the study.

follow-up was adjusted for in the sample size. To achieve a hazard ratio (HR) of at least 2.0 based on a 3-year survival rate, a minimum of 66 events of failure (deaths) were needed to achieve a power of $80 \%$.

\section{Variables and Measurements}

The retrieved data included patient demographics (age, sex) and pathological factors such as CRC location, stage and grade of CRC tumor. On the incidence date the age in completed years was defined as the age at diagnosis. The location of the colon tumour was right sided if the tumour was situated in the caecum, ascending colon and transverse colon and left sided if the colon tumour was located in the splenic flexure, descending colon, sigmoid colon, rectosigmoid colon and rectum. CRC tumors located $<15 \mathrm{~cm}$ from the anal verge connected to the mesorectal fascia or beneath the imaginary line of the promontorium were classified as rectal tumors. Rectosigmoid tumors were located $15 \mathrm{~cm}$ from the anal verge at the junction of the rectum and sigmoid colon. Tumors $>15 \mathrm{~cm}$ from the anal verge were classified as sigmoid tumors. The radiological staging system was used to stage CRC and the TNM stage was scored on the date of diagnosis according to the American Joint Committee on Cancer (AJCC) edition 2017. ${ }^{13}$ 
The diagnosis was confirmed to be invasive adenocarcinoma of the colon or rectum on H\&E slide examination and the histological grade of CRC was determined using the WHO classification system: well differentiated (G1), moderately differentiated (G2) or poorly differentiated (G3). ${ }^{14,15}$

Since the treatment of participants was by different healthcare professionals and in different hospitals it was not standardized. Treatment factors included whether they had surgery and the type of surgery (right or left sided colon cancer surgery or rectal cancer surgery) and/or chemotherapy and radiotherapy.

Right-sided colon operations were defined by location of tumour (caecum, ascending colon, hepatic flexure and proximal transverse colon) and involved curative right hemicolectomy and curative extended right hemicolectomy. Leftsided colon operations were defined by the location of the tumour (distal transverse colon, splenic flexure, descending colon and sigmoid colon) and involved curative left hemicolectomy and curative sigmoid colectomy. Rectal tumour operations involved curative low anterior resections and curative abdomino-perineal resections. Palliative colostomy was given to some patients who had unresectable tumours.

\section{Statistical Analysis}

We summarised patient characteristics by medians (interquartile range) or means (standard deviation) for continuous variables depending on the distribution and percentages for categorical variables. We calculated and plotted survival using Kaplan-Meier methods and compared the overall survival using the Log rank test. Cox proportional hazards $(\mathrm{PH})$ regression models were used to determine the hazard ratio (HR) for the factors associated with survival. Variables were assessed for collinearity before multivariable model building. Multivariate analysis involved a stepwise approach where variables with a $\mathrm{p}$ value of $\leq 0.2$ at bivariate were included and dropped after turning out with a $\mathrm{p}>0.05$ at multivariable model building. Further variables highlighted in the literature to have an effect on survival, in particular age and sex, were included even when they failed to meet the multivariable inclusion criteria. The proportion hazards (PH) assumption was evaluated for each variable included in the final model. All the data was analysed using STATA version 14.0. ${ }^{65}$ In all statistical tests a p-value of less than 0.05 was considered statistically significant.

\section{Results}

A total of 247 patients diagnosed with colorectal adenocarcinoma between January 2008 and December 2018 met the inclusion criteria for this study (Figure 1). There were 132 (53.4\%) females and the mean (standard deviation (SD)) age of the patients was 53.3 (15.7) years with the majority (49.4\%) of them in the 50-74 year age group. The female to male ratio was 1.14:1. More than half of the total patients (55.8\%) were diagnosed with stage III CRC, while $13.2 \%$ were diagnosed with stage IV CRC at presentation. A small proportion of patients (14.2\%) presented with early stage I CRC.

The majority of patients were diagnosed with T3 (45.3\%), N1 (44.7\%) and 57.7\% were moderately differentiated. Other demographic, baseline pathological and clinical characteristics are described in Table 1.

\section{Location of Primary Tumour}

Among the anatomic sites involved, the rectum was the primary cancer site involved in $122(49.4 \%)$ patients while tumours were found in the sigmoid colon in $61(24.7 \%)$ patients. Table 2 summarises the location of the primary colorectal tumours.

\section{Distribution of T (Depth of Tumor) Stage and N (Lymph Node Involvement) Stage}

The distribution of $\mathrm{T}$ stage was not statistically significant for left-sided colon tumours compared to right-sided colon tumours (Table 3). The distribution of $\mathrm{N}$ stage was not statistically significant for left-sided colon tumors compared to right-sided colon tumours. The distribution of the grade was also not statistically significant for left-sided colon tumours compared to right-sided colon tumours. 
Table I Baseline Characteristics of Study Participants

\begin{tabular}{|c|c|c|c|}
\hline Characteristic & Colon $\mathrm{n}(\%)$ & Rectal n(\%) & Total n(\%) \\
\hline \multicolumn{4}{|l|}{ Sex } \\
\hline Male & $59(47.2)$ & $56(45.9)$ & $115(46.6)$ \\
\hline Female & $66(52.8)$ & $66(54.1)$ & $132(53.4)$ \\
\hline \multicolumn{4}{|l|}{ Age } \\
\hline Median (interquartile range (IQR)) & $56(42-65)$ & $52(40-64)$ & $54(42-65)$ \\
\hline \multicolumn{4}{|l|}{ Topography } \\
\hline Right ccolon & & & $39(15.8)$ \\
\hline Left colon & & & $86(34.8)$ \\
\hline Rectum & & & $122(49.4)$ \\
\hline \multicolumn{4}{|l|}{ Clinical Stage } \\
\hline I & $13(10.4)$ & $14(11.5)$ & $27(10.9)$ \\
\hline ॥ & $19(15.2)$ & $13(10.7)$ & $32(13.0)$ \\
\hline III & $60(48.0)$ & $46(37.7)$ & $106(42.9)$ \\
\hline IV & II (8.8) & $14(11.5)$ & $25(10.1)$ \\
\hline \multicolumn{4}{|l|}{ Tumor Ssize } \\
\hline TI & $7(6.8)$ & $10(11.5)$ & $17(9.0)$ \\
\hline $\mathrm{T} 2$ & $18(17.5)$ & $17(19.5)$ & $35(18.4)$ \\
\hline T3 & $54(52.4)$ & $32(36.8)$ & $86(45.3)$ \\
\hline $\mathrm{T} 4$ & $24(23.3)$ & $28(32.2)$ & $52(27.4)$ \\
\hline \multicolumn{4}{|l|}{ Lymph Node Involvement } \\
\hline No & $34(33.0)$ & $29(33.3)$ & $63(33.2)$ \\
\hline NI & $47(45.6)$ & $38(43.7)$ & $85(44.7)$ \\
\hline $\mathrm{N} 2+\mathrm{N} 3$ & $22(21.4)$ & $20(23.0)$ & $42(22.1)$ \\
\hline \multicolumn{4}{|l|}{ Metastasis } \\
\hline Mo & $92(89.3)$ & $73(83.9)$ & $165(86.8)$ \\
\hline MI & II (10.7) & $14(16.1)$ & $25(13.2)$ \\
\hline \multicolumn{4}{|l|}{ Grading of the CRC } \\
\hline Well Differentiated aAadenocarcinoma & $29(31.5)$ & $34(31.2)$ & $63(31.3)$ \\
\hline Moderately Differentiated aAadenocarcinoma & $53(57.6)$ & $63(57.8)$ & $116(57.7)$ \\
\hline Poorly Differentiated aAadenocarcinoma & $10(10.9)$ & $12(1 \mathrm{I} .0)$ & $22(11.0)$ \\
\hline
\end{tabular}

\section{Comparison of Topography for Different Stages of Colorectal Carcinoma}

Table 4 shows that for stages I, III and IV disease, mortality among right-sided colon cancer was high compared to leftsided colon cancer (HR: 3.38; 1.09; 3.87); however, this did not reach statistical significance. For stage II disease, 
Table 2 Location of Primary Colorectal Tumour

\begin{tabular}{|l|l|l|}
\hline CRC Location & Frequency & Percent (\%) \\
\hline Caecum & 11 & 4.5 \\
\hline Ascending colon & 21 & 8.5 \\
\hline Transverse colon & 7 & 2.8 \\
\hline Descending colon & 18 & 7.3 \\
\hline Sigmoid colon & 61 & 24.7 \\
\hline Rectosigmoid junction & 7 & 2.8 \\
\hline Rectum & 122 & 49.4 \\
\hline
\end{tabular}

Table 3 Distribution of Radiological and Pathological Characteristics of Left Sided and Right Sided Colon Cancers

\begin{tabular}{|c|c|c|c|c|}
\hline Characteristics & Categories & $\begin{array}{l}\text { Right Sided Colon Cancer } \\
\text { (\%) }\end{array}$ & $\begin{array}{l}\text { Left Sided Colon Cancer } \\
\text { (\%) }\end{array}$ & P-value \\
\hline \multirow[t]{4}{*}{ Tumor Depth } & TI & $4(57.1)$ & $3(42.9)$ & \multirow[t]{4}{*}{0.312} \\
\hline & $\mathrm{T} 2$ & $4(22.2)$ & $14(77.8)$ & \\
\hline & T3 & $15(27.8)$ & $39(72.2)$ & \\
\hline & T4 & $9(37.5)$ & $15(62.5)$ & \\
\hline \multirow{3}{*}{$\begin{array}{l}\text { Lymph Node } \\
\text { Involvement }\end{array}$} & No & II (32.4) & $23(67.6)$ & \multirow[t]{3}{*}{0.962} \\
\hline & $\mathrm{NI}$ & $14(29.8)$ & $33(70.2)$ & \\
\hline & $\mathrm{N} 2+\mathrm{N} 3$ & $7(31.8)$ & $15(68.2)$ & \\
\hline \multirow[t]{2}{*}{ Metastasis } & MO & $29(31.5)$ & $63(68.5)$ & \multirow[t]{2}{*}{0.773} \\
\hline & MI & $3(27.2)$ & $8(72.7)$ & \\
\hline \multirow[t]{3}{*}{ Grade } & Well differentiated & $7(24.1)$ & $22(75.9)$ & \multirow[t]{3}{*}{0.308} \\
\hline & Moderately differentiated & $16(30.2)$ & $37(69.8)$ & \\
\hline & Poorly differentiated & $5(50.0)$ & $5(50.0)$ & \\
\hline
\end{tabular}

mortality among right-sided colon cancer was low compared to left-sided colon cancer (HR: 0.57); however, this did not reach statistical significance.

\section{Types of Treatment}

Among the 247 CRC patients, 177 (71.7\%) had curative surgical resection only, 7 (2.8\%) had a palliative colostomy and $63(25.5 \%)$ had no curative colon or rectal cancer surgery. Overall 65 (26.3\%) patients received a combination of curative surgery and adjuvant chemotherapy and only 3 patients received radiotherapy after rectal cancer surgery. Of the 177 patients who underwent curative surgery, 63 (35.6\%) underwent curative left-sided colon resections whilst $32(18.1 \%)$ had curative right-sided colon resections, and 82 (46.3\%) underwent curative rectal cancer surgery. 
Table 4 Comparison of Mortality Risk for Topography and Type of Operation by Stage

\begin{tabular}{|c|c|c|c|c|c|}
\hline & \multicolumn{2}{|l|}{ Risk Set } & HR & $95 \% \mathrm{Cl}$ & p-value \\
\hline \multicolumn{6}{|c|}{ Mortality Risk by Topography } \\
\hline Stage & $\begin{array}{l}\text { I } \\
\text { II } \\
\text { III }\end{array}$ & $\begin{array}{l}\text { Left sided colon cancer } \\
\text { Right sided colon cancer } \\
\text { Left sided colon cancer } \\
\text { Right sSided colon cancer } \\
\text { Left sSided colon cancer } \\
\text { Right sided colon cancer } \\
\text { Left sided colon cancer } \\
\text { Right sided colon cancer }\end{array}$ & $\begin{array}{l}1.00 \\
3.38 \\
1.00 \\
0.57 \\
1.00 \\
1.09 \\
1.00 \\
3.87\end{array}$ & $\begin{array}{l}0.31-37.5 \\
0.12-2.65 \\
00.56-2.13 \\
0.77-19.47\end{array}$ & $\begin{array}{l}0.321 \\
0.473 \\
0.799 \\
0.101\end{array}$ \\
\hline \multicolumn{6}{|c|}{ Mortality Risk by Type of Colon Operations } \\
\hline Stage & $\begin{array}{l}\text { I } \\
\text { II } \\
\text { III }\end{array}$ & $\begin{array}{l}\text { Right sided colon operations } \\
\text { Left sided colon operations } \\
\text { Right sided colon operations } \\
\text { Left sided colon operations } \\
\text { Right sided colon operations } \\
\text { Left sided colon operations } \\
\text { Right sided colon operations } \\
\text { Left sided colon operations }\end{array}$ & $\begin{array}{l}1.00 \\
3.38 \\
1.00 \\
1.65 \\
1.00 \\
0.74 \\
1.00 \\
0.58\end{array}$ & $\begin{array}{l}0.35-7.72 \\
0.35-1.57 \\
0.08-4.26\end{array}$ & $\begin{array}{l}0.524 \\
0.428 \\
0.59\end{array}$ \\
\hline \multicolumn{6}{|c|}{ Mortality Risk by Colon Compared to Rectal Operations } \\
\hline Stage & $\begin{array}{l}\text { I } \\
\text { II } \\
\text { III }\end{array}$ & $\begin{array}{l}\text { Rectal Operations } \\
\text { Left or Right Colon } \\
\text { operations } \\
\text { Rectal Operations } \\
\text { Left or Right Colon } \\
\text { operations } \\
\text { Rectal Operations } \\
\text { Left or Right Colon } \\
\text { operations } \\
\text { Rectal Operations } \\
\text { Left or Right Colon } \\
\text { operations }\end{array}$ & $\begin{array}{l}1.00 \\
0.31 \\
1.00 \\
1.91 \\
\\
1.00 \\
0.78 \\
\\
1.00 \\
0.32\end{array}$ & $\begin{array}{l}0.03-2.99 \\
0.70-5.18 \\
0.46-1.35 \\
0.05-1.95\end{array}$ & $\begin{array}{l}0.311 \\
0.205 \\
0.375 \\
0.217\end{array}$ \\
\hline
\end{tabular}

\section{Type of Operation}

For stages I and II, left-sided colon operations had a higher risk of mortality than right-sided colon operations; however, this did not reach statistical significance (Stage II: HR=1.65). For stage III and stage IV, left-sided colon operations had a lower risk of mortality than right-sided colon operations; however, this did not reach statistical significance (Stage III $\mathrm{HR}=0.74$; Stage IV HR=0.58).

For stage II, colon operations had a higher mortality than rectal operations however this did not reach statistical significance $(\mathrm{HR}=1.91)$. For stages I, III, IV and missing stage, colon operations had a lower mortality than rectal operations; however, this did not reach statistical significance (Stage I:HR=0.31; Stage III: HR=0.78; Stage IV:HR=0.32; Missing stage: $\mathrm{HR}=0.92$ ).

\section{Overall Survival}

Figure 2 shows that the 3-year overall survival after diagnosis was 33.3\% (95\% CI, 27.3-39.4). Table 5 indicates overall survival estimates at 1,2 and 3 years for selected baseline variables; the proportion of males surviving at 3 years was $32.3 \%$ (95\% CI, 23.6-41.2\%) and was not statistically significant from that of females (34.1\% (95\% CI: $25.9-42.5 \%)$ ). 
The 3-year survival proportions were 31.3\% (95\% CI 22.2-40.8\%), 35.6\% (95\% CI, 26.9-44.3\%) and 29.9\% (95\% CI, 13.4-48.5\%) for patients who were diagnosed with CRC at $<49$ years, 50-74 years and $>75$ years respectively.

As illustrated by Table 5 and Figure 3, patients with higher clinical stage at baseline had lower 3-year overall survival than those with stage I disease.

\section{Factors Associated with the Survival of Colorectal Adenocarcinoma Patients}

Table 6 indicates that in the bivariate analysis, patients with stage II, III and IV disease were 2.27 (95\% CI, 1.03-5.00), 2.54 (95\% CI, 1.27-5.09) and 5.67 (95\% CI, 2.61-12.31) times more likely to die than patients with stage I disease. The risk of death was 1.67 (95\% CI, 1.09-2.56) times higher among patients with N1 disease and 1.90 (95\% CI, 1.16-3.12) times higher among patients with $\mathrm{N} 2$ or N3 lymph node involvement. Patients with metastasis (M1) were associated with a mortality risk of 2.64 (95\% CI, 1.67-4.18) times compared to those with no metastasis (M0). Age, sex, grade, topography and type of surgery were not associated with mortality in the bivariate analysis.

In the multivariate analysis, stage II ( $\mathrm{aHR}=2.38,95 \% \mathrm{CI}, 1.08-5.26)$, stage III (aHR=2.62, 95\% CI, 1.30-5.30) and stage IV (aHR=2.26-11.52) were significantly associated with the risk of mortality. However, curative surgery alone $(\mathrm{aHR}=0.64,95 \% \mathrm{CI}, 0.43-0.95)$ and curative surgery with chemotherapy (aHR=0.54, 95\% CI, 0.34-0.86) were significantly associated with a reduction in the risk of mortality.

Figure 4 shows that for surgery, the one-year survival was $65.5 \%$, the two-year survival was $46.5 \%$ and the 3 -year survival was $41.0 \%$. For no surgery, the one-year survival was $62.5 \%$, the two-year survival was $27.0 \%$ and the 3 -year survival was $10.1 \%$. Surgery had a better overall survival than no curative surgery and this reached statistical significance $(\mathrm{p}=0.0003)$.

Figure 5 shows that for surgery and chemotherapy the one-year survival was $32.7 \%$, the two-year survival was $54.6 \%$ and the three-year survival was $57.7 \%$. Surgery followed by chemotherapy had a better overall survival than no surgery and chemotherapy, and this reached statistical significance $(\mathrm{p}=0.004)$.

\section{Discussion}

Over the past decade, there has been an improvement in the survival rates of colorectal carcinoma patients globally, particularly due to more effective treatments and early detection of CRC. ${ }^{16}$ However, in low-income developing

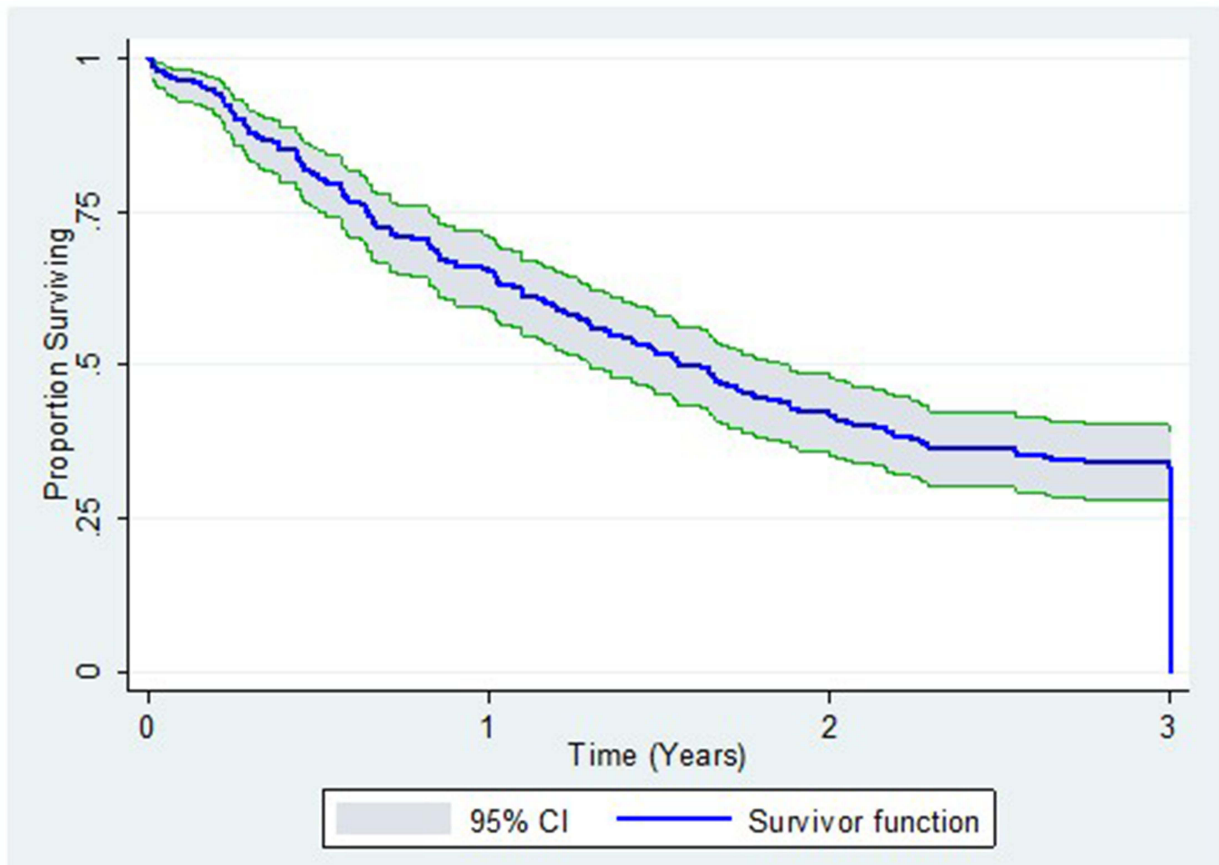

Figure 2 3-year overall colorectal cancer survival. 
Table 5 Survival Estimates at I, 2 and 3 Years for Selected Baseline Characteristics

\begin{tabular}{|c|c|c|c|c|c|}
\hline Characteristic (s) & Time Point & $\begin{array}{l}\text { Number } \\
\text { Beginning }\end{array}$ & $\begin{array}{l}\text { Number } \\
\text { Dead }\end{array}$ & $\begin{array}{l}\text { Proportion Surviving } \\
\text { (\%) }\end{array}$ & $\begin{array}{l}95 \% \text { Confidence } \\
\text { Interval }\end{array}$ \\
\hline \multirow[t]{3}{*}{ Overall } & I year & 150 & 83 & 65.2 & $58.8-70.9$ \\
\hline & 2 years & 97 & 53 & 42.0 & $35.6-48.3$ \\
\hline & 3 years & 76 & 20 & 33.3 & $27.3-39.4$ \\
\hline \multirow[t]{3}{*}{ Male } & I year & 70 & 38 & 65.5 & $55.7-73.6$ \\
\hline & 2 years & 42 & 28 & 38.9 & $29.7-48.0$ \\
\hline & 3 years & 34 & 7 & 32.3 & $23.6-41.2$ \\
\hline \multirow[t]{3}{*}{ Female } & I year & 81 & 45 & 65.0 & $56.0-72.6$ \\
\hline & 2 years & 56 & 25 & 44.7 & $35.8-53.1$ \\
\hline & 3 years & 42 & 13 & 34.1 & $25.9-42.5$ \\
\hline \multirow[t]{3}{*}{$\leq$ Median Age (54.0) } & I year & 75 & 51 & 59.9 & $50.8-67.8$ \\
\hline & 2 years & 45 & 30 & 35.6 & $27.3-44.0$ \\
\hline & 3 years & 36 & 8 & 29.1 & $21.4-37.3$ \\
\hline \multirow[t]{3}{*}{ Above Median Age (>54.0) } & I year & 76 & 32 & 71.3 & $61.9-78.8$ \\
\hline & 2 years & 53 & 23 & 49.4 & $39.7-58.5$ \\
\hline & 3 years & 40 & 12 & 38.0 & $28.9-47.1$ \\
\hline \multirow[t]{3}{*}{ Stage I } & I year & 21 & 4 & 84.7 & $64.0-94.0$ \\
\hline & 2 years & 19 & 2 & 76.2 & $54.3-88.6$ \\
\hline & 3 years & 15 & 3 & 63.5 & $41.4-79.2$ \\
\hline \multirow[t]{3}{*}{ Stage II } & I year & 25 & 7 & 77.9 & $59.1-88.8$ \\
\hline & 2 years & 13 & 12 & 38.9 & $22.2-55.4$ \\
\hline & 3 years & 11 & 1 & 35.7 & $19.6-52.2$ \\
\hline \multirow[t]{3}{*}{ Stage III } & I year & 66 & 38 & 63.5 & $53.4-71.9$ \\
\hline & 2 years & 44 & 22 & 42.0 & $32.4-51.3$ \\
\hline & 3 years & 32 & 11 & 31.2 & $22.6-40.3$ \\
\hline \multirow[t]{3}{*}{ Stage IV } & I year & 10 & 15 & 38.4 & $19.7-56.9$ \\
\hline & 2 years & 4 & 6 & 12.8 & $3.2-29.2$ \\
\hline & 3 years & 1 & 2 & 4.3 & $0.3-17.9$ \\
\hline \multirow[t]{3}{*}{ Palliative Surgery } & I year & 6 & 1 & 83.3 & $27.3-97.5$ \\
\hline & 2 years & 5 & 1 & 66.7 & $19.5-90.4$ \\
\hline & 3 years & 3 & 1 & 50.0 & $11.1-80.4$ \\
\hline \multirow[t]{3}{*}{ Curative Surgery Aalone } & I year & 69 & 39 & 65 & $55.3-73.1$ \\
\hline & 2 years & 50 & 18 & 47.5 & $37.8-56.6$ \\
\hline & 3 years & 42 & 7 & 40.7 & $31.3-49.9$ \\
\hline
\end{tabular}


Table 5 (Continued).

\begin{tabular}{|l|l|l|l|l|l|}
\hline Characteristic (s) & Time Point & $\begin{array}{l}\text { Number } \\
\text { Beginning }\end{array}$ & $\begin{array}{l}\text { Number } \\
\text { Dead }\end{array}$ & $\begin{array}{l}\text { Proportion Surviving } \\
\text { (\%) }\end{array}$ & $\begin{array}{l}\text { 95\% Confidence } \\
\text { Interval }\end{array}$ \\
\hline \multirow{2}{*}{$\begin{array}{l}\text { No Surgery and No } \\
\text { Chemotherapy }\end{array}$} & 1 year & 28 & 21 & 57.2 & $42.2-69.7$ \\
\cline { 2 - 6 } & 2 years & 14 & 14 & 27.6 & $15.8-40.6$ \\
\cline { 2 - 6 } & 3 years & 5 & 8 & 10.6 & $3.9-21.2$ \\
\hline \multirow{3}{*}{ Curative Surgery + Chemotherapy } & 1 year & 41 & 20 & 66.8 & $53.4-77.2$ \\
\cline { 2 - 6 } & 2 years & 28 & 25 & 45.1 & $32.3-57.1$ \\
\cline { 2 - 6 } & 3 years & 25 & 41.8 & $29.3-53.8$ \\
\hline
\end{tabular}

countries in East Africa, CRC is still a significant cause of mortality. The current work investigated the survival rate and predictors of survival among CRC patients in Uganda.

In our study, the survival rate among CRC patients was low. At 3 years after diagnosis, only one- third of patients survived, and survival was independently associated with the clinical stage of cancer at diagnosis as well as cancer treatment. High clinical stage at diagnosis was associated with an elevated risk of mortality, whereas curative surgery or curative surgery in combination with chemotherapy was associated with a reduced risk of mortality.

The rate of survival of $33.3 \%$ observed in our study is comparable to the low survival rates found in other studies from low-income developing countries in Sub-Saharan Africa. The three-year survival rates in Ghana were found to be $21 \%$ (10), those in Kenya $40 \%{ }^{17}$ and those in Ethiopia were $47 \% .{ }^{18}$ These three-year survival rates in Sub-Saharan Africa are lower than those from studies conducted in England (3-year survival for colon carcinoma: 69.5\%; 3-year survival for rectal carcinoma: 69.7\%), ${ }^{19}$ Taiwan $(79.4 \%),{ }^{20}$ Malaysia $(55.04 \%),{ }^{21}$ Kurdistan $(57 \%),{ }^{22}$ Jordan $(66 \%)^{23}$ and Northern Iran (52\%). ${ }^{24}$ The survival rates of CRC in high-income developed countries such as the United States, parts of Europe, Canada, Australia and New Zealand are better than ours, ${ }^{1}$ even though these countries report higher CRC

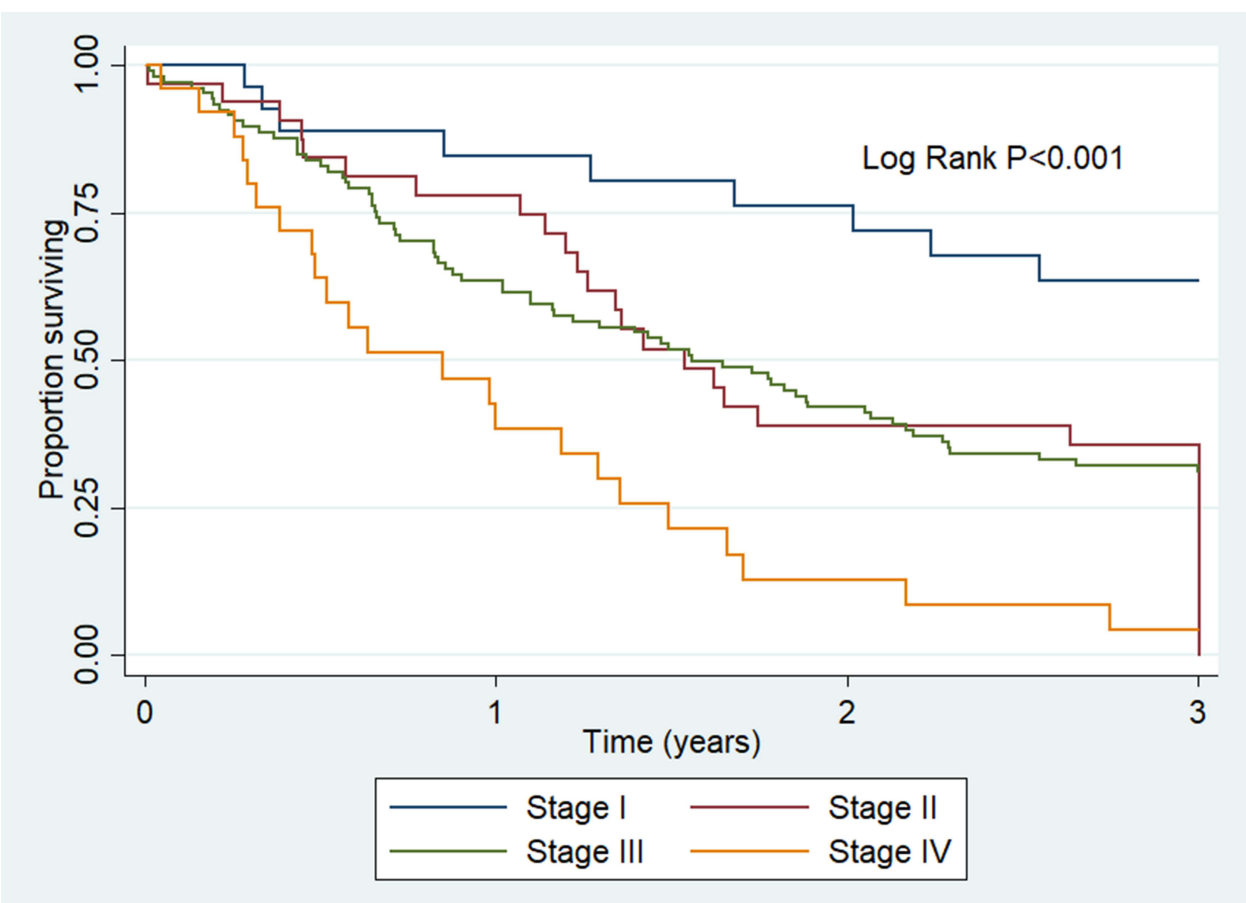

Figure 3 3-year colorectal cancer survival by stage. 
Table 6 Factors Associated with the Risk of Mortality Among CRC Patients in Uganda

\begin{tabular}{|c|c|c|c|c|c|c|c|}
\hline Characteristic (s) & Category & Crude Hazard Ratio (cHR) & $95 \% \mathrm{Cl}$ & p-value & Adjusted Hazard Ratio (aHR) & $95 \% \mathrm{Cl}$ & p-value \\
\hline \multirow[t]{2}{*}{ Sex } & Male & 1.00 & & & 1.00 & & \\
\hline & Female & 0.99 & $0.72-1.35$ & 0.928 & 1.03 & $0.72-1.49$ & 0.858 \\
\hline \multirow[t]{2}{*}{ Age } & $\leq 54$ & 1.00 & & & 1.00 & $0.99-1.01$ & 0.634 \\
\hline & $>54$ & 0.74 & $0.54-1.01$ & 0.061 & 0.76 & $0.53-1.10$ & 0.152 \\
\hline \multirow[t]{4}{*}{ Clinical Stage } & I & 1.00 & & & 1.00 & & \\
\hline & II & 2.30 & $1.04-5.04$ & 0.039 & 2.44 & $1.10-5.4 \mid$ & 0.028 \\
\hline & III & 2.56 & $1.28-5.14$ & 0.008 & 2.65 & $1.31-5.39$ & 0.007 \\
\hline & IV & 5.85 & $2.69-12.74$ & $<0.001$ & 5.47 & $2.40-12.48$ & $<0.001$ \\
\hline \multirow[t]{3}{*}{ Grade* } & Well Differentiated & 1.00 & & & & & \\
\hline & Moderately Differentiated & 0.78 & $0.53-1.14$ & 0.194 & & & \\
\hline & Poorly Differentiated & 0.81 & $0.44-1.48$ & 0.499 & & & \\
\hline \multirow[t]{4}{*}{ Depth of Tumor Invasion* } & TI & 1.00 & & & & & \\
\hline & $\mathrm{T} 2$ & 1.09 & $0.44-2.69$ & 0.855 & & & \\
\hline & T3 & 2.00 & $0.91-4.39$ & 0.085 & & & \\
\hline & $\mathrm{T} 4$ & 3.84 & I.73-8.54 & 0.001 & & & \\
\hline \multirow[t]{3}{*}{ Lymph Node Involvement* } & No & 1.00 & & & & & \\
\hline & $\mathrm{NI}$ & 1.67 & $1.09-2.56$ & 0.020 & & & \\
\hline & $\mathrm{N} 2+\mathrm{N} 3$ & 1.90 & $1.16-3.12$ & 0.011 & & & \\
\hline \multirow[t]{2}{*}{ Metastasis* } & Mo & 1.00 & & & & & \\
\hline & MI & 2.64 & $1.67-4.18$ & $<0.001$ & & & \\
\hline \multirow[t]{3}{*}{ Topography } & Rectum & 1.00 & & & & & \\
\hline & Right colon & 0.88 & $0.56-1.39$ & 0.581 & & & \\
\hline & Left colon & 0.80 & $0.56-1.14$ & 0.210 & & & \\
\hline \multirow[t]{4}{*}{ Type of Surgery } & Right-sided colon operations & 1.00 & & & & & \\
\hline & Left-Sided colon operations & 0.83 & $0.47-1.47$ & 0.529 & & & \\
\hline & All rectal operations & 1.00 & & & & & \\
\hline & All colon operations & 0.94 & $0.63-1.39$ & 0.752 & & & \\
\hline \multirow[t]{4}{*}{ Treatment Combinations } & No curative surgery or chemotherapy & 1.00 & & & 1.00 & & \\
\hline & Curative Surgery + chemotherapy & 0.54 & $0.35-0.84$ & 0.006 & 0.53 & $0.32-0.88$ & 0.015 \\
\hline & Chemotherapy alone & 1.00 & $0.50-1.99$ & 0.998 & 0.69 & $0.32-1.50$ & 0.352 \\
\hline & Curative Surgery alone & 0.55 & $0.37-0.81$ & 0.003 & 0.63 & $0.39-1.01$ & 0.057 \\
\hline
\end{tabular}

Notes: *Variable not included in multivariate model because of collinearity. 


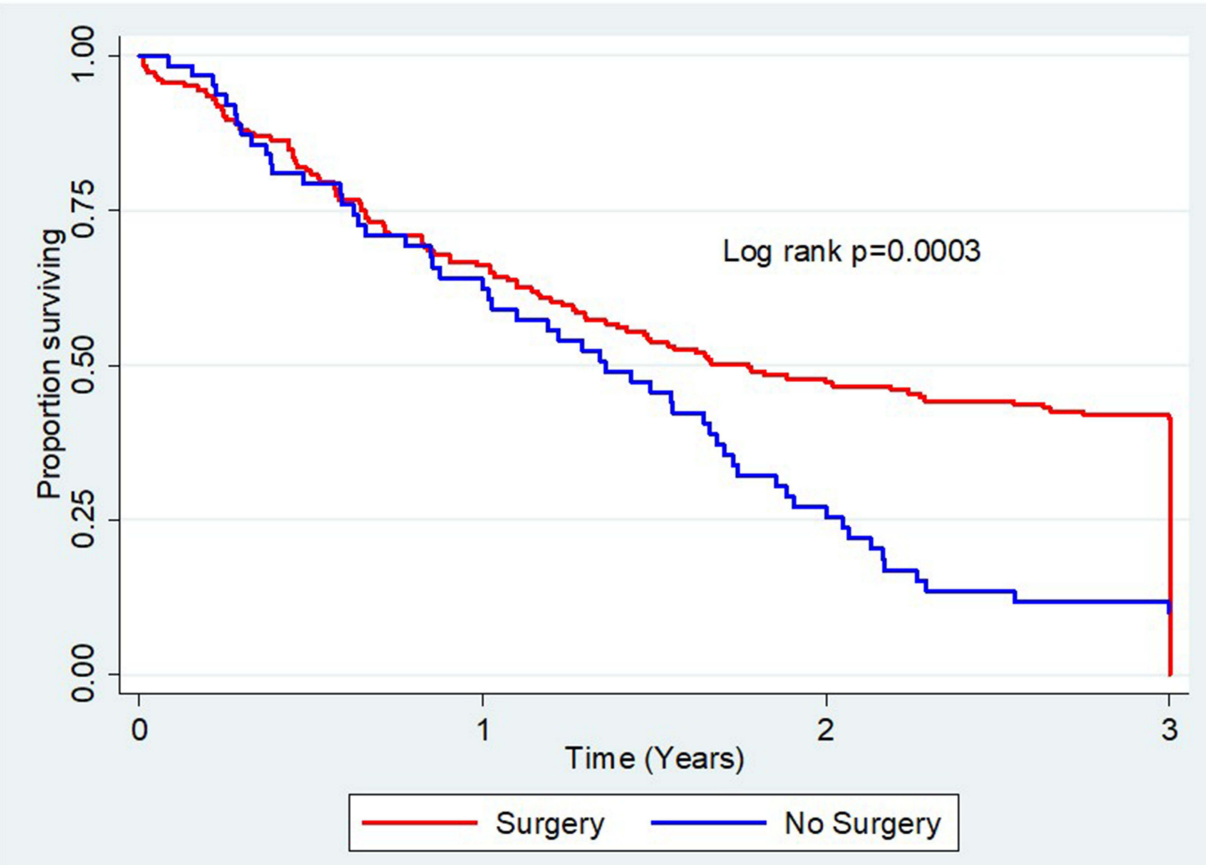

Figure 4 Kaplan-Meier estimates of curative surgery alone, which has better survival rates than no surgery.

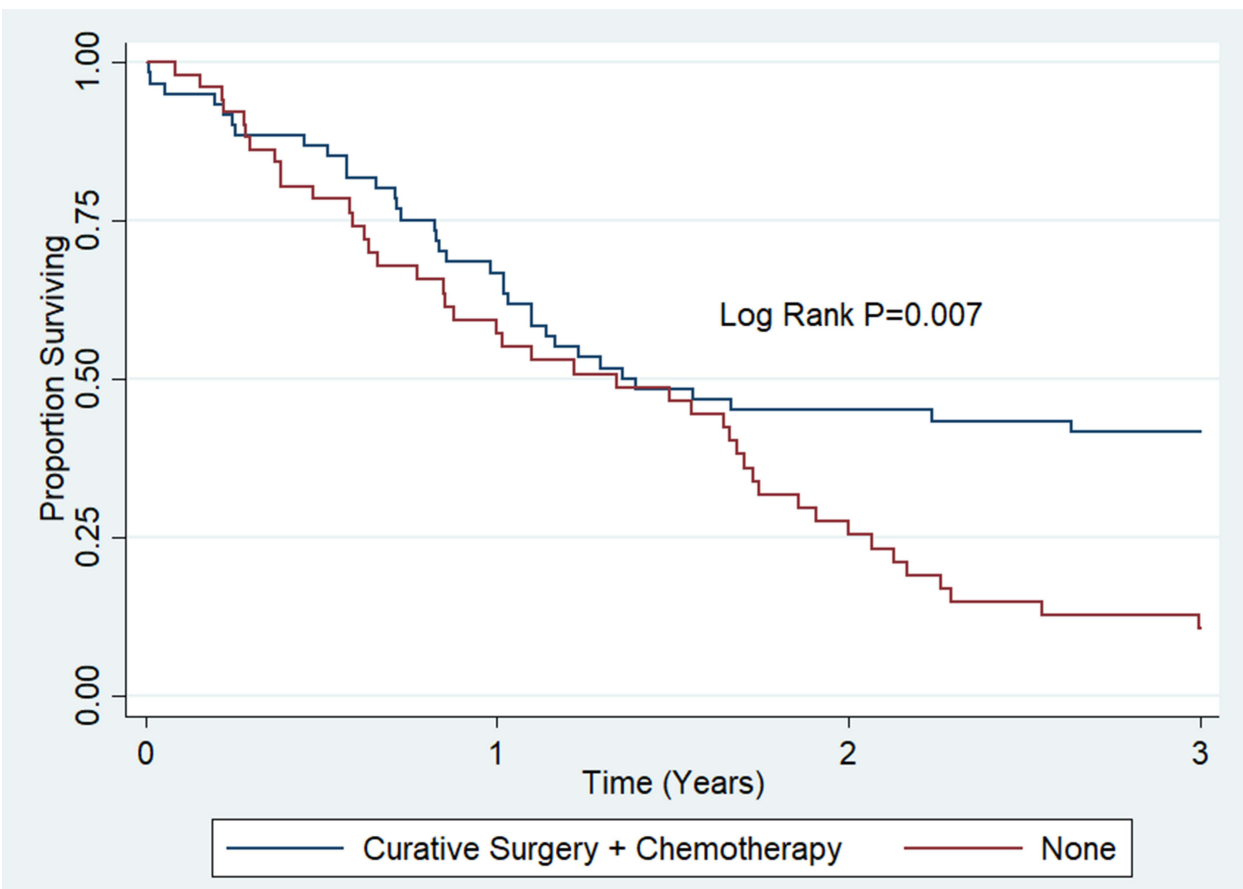

Figure 5 Kaplan-Meier estimates showing better survival rates with curative surgery and chemotherapy. 
incidence rates. The effectiveness of colorectal cancer screening programmes, lack of modernised infrastructure for CRC care and lack of curative treatment may account for the disparities in the survival rates among low income developing countries and high income developed countries.

Possible reasons behind the poor survival rates in low income developing countries may also include low socioeconomic circumstances, delayed individual health seeking behaviour, inadequacies and limitations in health systems and a lack of prioritisation for non-communicable diseases. ${ }^{25}$ Specifically there is a lack of capacity to perform effective screening to detect early CRC as well as a lack of diagnostic services such as colonoscopy and treatment facilities. However, there are several prognostic factors that may influence patient survival.

\section{Age}

In our study, age was not identified as a prognostic factor influencing survival. This is consistent with the results from other studies in Africa and Asia. ${ }^{10,26-29}$ Other recent studies have shown conflicting results and report poorer survival with older age as a prognostic factor. ${ }^{30-34}$ The median age in this study was 54 years. This median age was comparable to that reported in South African studies. ${ }^{35,36}$ However, in developed Western countries in the UK, the median age is 73 years and in the US, it is 70 years. In the US, $17.4 \%$ of CRC patients were diagnosed under the age of 54 years, while in the UK, only $16 \%$ of CRC patients had a diagnosis under 60 years of age. ${ }^{37,38}$ Therefore, the high rate of patients diagnosed with CRC under 50 years and the lower median age reported in Uganda resulted in age not being a prognostic factor for survival in our study.

\section{Gender}

Most studies have shown that sex plays no prognostic role in predicting survival. ${ }^{27,29,33,39}$ This finding is consistent with the results of our study. However, some studies have shown contradictory results, where poorer survival was found in male patients. ${ }^{40-42}$ The reason may be due to the different proportions of rectal and colon cancer patients involved in these studies. Other contributing factors include differences in risk behaviours (physical activity and smoking) and different levels of health awareness. ${ }^{41}$

\section{Stage of CRC}

At diagnosis, the stage of colorectal cancer has been found to influence survival. In our study a poorer survival outcome was registered in patients who had an advanced stage of CRC at baseline. This finding is in agreement with many studies that showed poorer survival associated with an advanced tumor stage. ${ }^{10,25,29,43}$ For the stage of colorectal carcinoma, the three-year survival rates in Ethiopia have been found to vary from $89.6 \%$ for stage I and $60.8 \%$ for stage II localized cancers. In the same study, stage III regional cancers had a 3-year survival rate of $44.5 \%$, and distant metastatic colorectal carcinomas (stage IV) had a poorer survival rate at $20.9 \%$. In our study, based on TNM staging, the overall survival was found to be $63.5 \%$ for stage I, $35.7 \%$ for stage II, $31.2 \%$ for stage III and $4.3 \%$ for stage IV. Using the Log rank test, we found a statistically significant difference in survival at bivariate and multivariate analyses among all the different CRC stages $(\mathrm{p}<0.05)$.

For early stage disease the survival rate was high despite all the limitations in health service delivery. This implies that making an early diagnosis is crucial to improve survival. Therefore, the lack of national screening programmes, lack of public health education regarding the prevention of CRC and lack of diagnostic techniques for efficient early diagnosis may be the reasons behind the low survival rates seen in this study. The majority of our participants, presented with stage III and stage IV disease. This stage was not revised at the time of death, so most patients with stage III advanced to stage IV disease. In this context, the staging of CRC mostly involved plain chest X-ray and ultrasound scanning, with some having a CT abdomen/pelvis. In low-resource environments such as ours, especially in rural parts of Uganda, CT scanning is largely inaccessible for many patients. Therefore, the CRC stage at diagnosis was likely to be underassessed with inadequately high precision staging capacity. Another reason for under assessing the CRC TNM stage in this study is that the stage recorded in our study was radiological at diagnosis and not pathological. Therefore, this underassessment in staging the colorectal tumours may also explain the lower survival observed for stage I CRC patients following curative surgery in our patient cohort. 


\section{Characteristics of CRC}

Among the characteristics of the tumor, the presence of lymph node involvement and the size of the primary tumor were linked to survival outcome in bivariate analysis. In this study, the presence of four or more lymph node metastases (N2) together with tumors extending to the outer layer of the bowel wall was associated with a poorer survival outcome. The presence of distant metastasis and hence stage IV colorectal carcinoma was also linked to a poor survival. However, the grade of colorectal adenocarcinoma differentiation did not influence survival. These findings, which are in agreement with several other reports, highlight the importance of TNM staging of the tumour as this has a significant impact on patient survival. ${ }^{10,44-46}$

\section{Location of CRC}

In contrast to other studies that have shown poorer survival rates for right-sided colon cancers, the findings of our study did not identify any differences in survival rates between the left colon and right colon. ${ }^{29,50,51}$ In a combined analysis of patients in stages I, II or III, we did not find any difference in survival rates across the different colon sites. The right colon did not have a worse prognosis than the left colon in stage III colon cancer. Stage III colon cancer did not have a worse prognosis than stage II colon cancer in the right colon. Many studies in the West have shown that left-sided colon tumors mainly present with early-stage CRC compared to right-sided colon tumors, which has resulted in the prognoses being different according to the CRC location (50). These same studies have shown that right-sided colon tumors present at an advanced stage compared to left-sided colon tumors. ${ }^{52-54}$ However, a study by Lim et al, showed that although $\mathrm{T}$ stage was not different between left-sided and right-sided colon carcinoma, the $\mathrm{N}$ stage was significantly higher in right sided colon carcinoma. ${ }^{55}$ These studies have shown that right-sided colon carcinoma tends to be more poorly differentiated, microsatellite instability positive and mucinous histologically associated with a poor prognosis than left-sided colon carcinoma. ${ }^{55-57}$ However, our study did not find any difference in grade and stage between the left colon and the right colonic tumours, which possibly explains the lack of difference in survival between the locations of colon tumours.

Our study and other studies from Sub-Saharan Africa have shown that rectal adenocarcinoma is more common in contrast to high income developed countries in which $65 \%$ are colonic tumors. ${ }^{66}$ This may probably be due to lack of screening programmes as rectal tumors tend to more commonly present with symptoms and signs such as rectal bleeding, rectal pain and changes in bowel habit. Compared to colon adenocarcinoma there is a distinct molecular landscape associated with rectal adenocarcinoma. ${ }^{67}$

\section{Type of Operation and Treatment Modalities}

In the absence of extensive metastases, surgery is considered the principal treatment for colorectal carcinoma. ${ }^{47}$ Generally, colon cancer patients in stage I received surgery only, whereas selected cases of stage II, all stage III and selected cases of stage IV colon cancers received surgery combined with chemotherapy. Stage I rectal cancers received surgery only, while for stage II, III and IV rectal cancers, treatment was surgery combined with postoperative chemotherapy and radiotherapy. Neoadjuvant chemoradiotherapy was not administered to any of the stage II or stage III rectal cancer patients and only a small number of rectal cancer patients received postoperative radiotherapy as these services are often lacking in Uganda. This may impact outcomes considering that radiotherapy has been found in many studies to reduce rectal tumor recurrence following curative resection. However, the impact on outcomes of this treatment modality could not be assessed in our study.

Our findings are in keeping with the results of other studies that found no significant differences in oncological outcome and survival following left versus right-sided curative colon resections. ${ }^{60}$ Therefore, tumour location is not an independent factor influencing prognosis following surgical treatment of colon carcinoma in our population. Advanced $\mathrm{T}$ stage, node positivity and poor histological grade were not independent prognostic variables influencing survival. However, our study showed that survival did improve with curative surgical resection among either colon or rectal cancer patients even though a large proportion of patients in our sample presented with advanced stages of CRC.

In contrast with reports from the SEER database in the US, our study showed no difference in survival following colon cancer surgery compared to rectal cancer surgery. According to the SEER database (1995-2008), for stage IIB, 
colon cancer however had a better outcome than rectal cancer. ${ }^{48}$ Rectal cancer patients had a longer survival than colon cancer patients for advanced stages IIIC and IV. ${ }^{48,49}$ The disparity in survival may be explained by differences in blood supply direction and hence metastasis or different underlying genetic factors. Therefore when considering prognosis, local factors are as important as lymph node metastasis. ${ }^{48,49}$ However in our study, the late stage presentations in both colon and rectal cancer patients with no difference in grade and lymph node involvement possibly explains the lack of difference in survival seen after surgery for colon cancer compared to rectal cancer in our population.

The total number of lymph nodes harvested from a right-sided colon tumour at surgery was found to be higher than that harvested from left-sided colon tumours. In right hemicolectomy and extended right hemicolectomy, the field of resection is wider compared to that in left hemicolectomy or anterior resection. This results in a higher rate of lymph node positivity for CRC. Therefore, right-sided colon carcinoma has been associated with a poorer prognosis in studies from the West especially for stage III colon cancers compared to left-sided colon tumours. ${ }^{56-59}$ However our study did not show poorer survival following curative surgery even with stage III right-sided colon cancers possibly due to the majority of both right-sided and left-sided colon cancers presenting in advanced stages with no significant difference in the tumor grade and lymph node involvement of the location of colon cancer.

The present study unequivocally demonstrated the benefit of curative surgery alone and also when combined with chemotherapy in stage II and stage III in the management of colon and rectum adenocarcinoma patients in Uganda. Our findings demonstrate that surgery followed by chemotherapy in stage II, III and IV colon and rectal cancer is crucial in addressing the increasing burden from colorectal carcinoma in Uganda. Therefore, curative surgical resection followed by chemotherapy, if necessary, should be advocated in low-income developing countries because it benefits survival. In Uganda, the incidence of CRC is lower than that in high-income developed countries; however, it is increasing, and the mortality rates are just as high due to differences in early diagnosis and treatment. ${ }^{1}$ The surgery and oncology capacity for cancer care in Uganda and other low-income developing countries in Sub-Saharan Africa is very limited. ${ }^{61}$ Therefore, many CRC patients will benefit from better access to surgery and oncology care, especially in the rural parts of Uganda. ${ }^{62,63}$ Survival is improved if and when curative surgery is available and is also improved when combined with adjuvant chemotherapy if necessary in colorectal carcinoma patients.

The majority of hospitals that participated in our study are referral centres for endoscopy and surgery services in Uganda. The survival outcomes seen in these hospitals emphasize the need for increasing endoscopy, surgery and oncology services in the country. Colonoscopy services are limited in rural hospitals in Uganda and Sub-Saharan Africa, ${ }^{9}$ and national screening guidelines for CRC in Uganda are currently not available. Although the majority of the hospitals in our study have endoscopy services there is a limitation on the uptake of preventive screening. The majority of patients tend to present with symptoms of CRC and therefore experience a long delay before attending hospital resulting in a presentation at a late stage when diagnosed. An improvement in survival will be experienced if these CRC patients have an earlier diagnosis and treatment. ${ }^{64}$

A substantial number of patients in this study did not undergo any surgery and only a few had a palliative colostomy, which may possibly be due to avoidance of a colostomy, referral for preoperative chemotherapy and radiotherapy but not returning for the operation due to the high costs of the operation involved. The creation of support groups and improvement in the coordination of CRC care by expanding the surgery and oncology infrastructure may be beneficial in Uganda and other low-income developing countries in Sub-Saharan Africa to help patients navigate around the difficulties of accessing appropriate treatment.

\section{Conclusions}

The survival rate for colorectal cancer patients in Uganda is generally within the range of other Sub-Saharan African countries but lower than that of high-income developed countries. More than half of our study population presented with advanced stage III and IV CRC, having a poorer survival than early-stage CRC. Clinical prognostic factors having an impact on colorectal cancer patient survival in Uganda included staging at diagnosis and treatment modalities, particularly in the form of curative surgery alone and curative surgery with chemotherapy. Providing more public health education, especially among the rural and low socioeconomic communities, may increase awareness to present early to hospital with symptoms and signs of colorectal cancer. Future implementation of a national screening programme for 
colorectal cancer is also recommended to make an early diagnosis of CRC and hence to improve the national survival rate of CRC in the Ugandan population. Molecular studies should be carried out to identify potential molecular markers in $\mathrm{CRC}$ that could influence prognosis and subsequently improve treatment in the Ugandan population.

\section{Study Strengths and Limitations}

Our study has the largest number of patients, mainly from referral hospitals in central Uganda, who receive CRC patients from different regions of the country. Therefore, our results can be generalised for all the country. Another strength of this study is the focus on an understudied CRC population in Uganda.

Several limitations were encountered in our study. Compared to high-income countries, difficulty was encountered in obtaining complete data from the medical records retrospectively. Selection bias could have possibly been introduced during the collection of secondary data from the Kampala Cancer Registry, as patients with no clinical data or missing demographic clinical data were excluded. However, our data was complete enough to contribute to understanding the predictors of survival of colorectal adenocarcinoma patients in Uganda despite this limitation.

In our setting, loss to follow-up of CRC patients from the surgery and oncology outpatient departments is a common problem. This was overcome with active follow-up of these patients by telephone calls and home visits in the community in different regions of Uganda. The loss to follow-up in this study was $6.07 \%$, which was less than the $10 \%$ loss to follow-up, which was taken into account when estimating the sample size.

A major limitation involved data being collected from the different hospitals, and surgical treatment was not standardised. Underestimating the stage was also another limitation as it was radiological and not pathological and some cases were not staged no CT scan but by ultrasound. Since the lymph node assessment in this study was radiological and not pathological, this could have underestimated the extent of lymph node involvement during surgery, hence influencing oncological outcome between the different surgical operations.

It would seem to be more appropriate to count the start of the survival time from the date of onset of colorectal cancer in the study participants. However, the date of histopathological diagnosis was used hence a time lag between the time the patients presented with symptoms and signs of CRC and a diagnosis being made may be long. This may have underestimated our overall survival rate. A significant proportion of our patients could have also died of causes unrelated to colorectal cancer, as postmortems were not carried out. Therefore, there could also have been underreporting of deaths leading to an overestimated survival rate.

\section{Abbreviations}

$\mathrm{SD}$, standard deviation; cHR, crude hazards ratio; aHR, adjusted hazards ratio; HR, hazard ratio; OS, overall survival; CRC, colorectal cancer; AJCC, American Joint Committee on Cancer.

\section{Data Sharing Statement}

The anonymized dataset used for this research is attached as Supplementary Table S1. The contents of this research article are the sole responsibility of the authors.

\section{Ethical Considerations}

This work was part of the PhD study, which was approved by the Higher Degrees Research and Ethics Committee, School of Biomedical Sciences, College of Health Sciences, Makerere University (reference number: SBS-HDREC-630) and Uganda National Council for Science and Technology (reference number: HS-2574). To access and abstract data from the Kampala Cancer Registry and data from case files in the respective hospitals, a waiver of consent was obtained from the Higher Degrees Research and Ethics Committee, School of Biomedical Sciences, College of Health Sciences, Makerere University. The patient data accessed from the Kampala Cancer Registry was anonymized and maintained with confidentiality. The accessed data therefore complied with relevant data and privacy regulations of the Kampala Cancer Registry. 


\section{Consent for Publication}

Written informed consent was obtained to actively follow up some of the participants in the community outside the catchment area of the Kampala Cancer Registry to determine their vital status. For those participants who had their vital status recorded in the Kampala Cancer Registry, the waiver of consent obtained from the Higher Degrees Research and Ethics Committee, School of Biomedical Sciences, College of Health Sciences, Makerere University was applied.

\section{Acknowledgments}

This was part of the PhD work, which was approved by the Doctoral Committee and Higher Degrees Research and Ethics Committee of the School of Biomedical Sciences, College of Health Sciences, Makerere University for the corresponding author. Final approval for this research study was obtained from Uganda National Council for Science and Technology.

The authors wish to thank clinical staff and research assistants in the Department of Surgery of Masaka Regional Referral Hospital, Mulago National Referral Hospital, Uganda Martyrs' Hospital Lubaga, Mengo Hospital and Hospice Africa Uganda for their support in this research project.

The authors also wish to thank Sarah Nambooze and Mary Phoebe Amulen, research assistants in the Kampala Cancer Registry, Department of Pathology, School of Biomedical Sciences, College of Health Sciences, Makerere University for collecting data from the Kampala Cancer Registry, data from the medical records of the study participants in the respective hospitals and active follow-up of participants in the community from different regions of the country.

\section{Funding}

The authors declare that they received no specific funding for this work. However, the corresponding author personally funded this part of his $\mathrm{PhD}$ research study. No payment was received by the authors to write and publish this article.

\section{Disclosure}

The authors declare that they have no competing interests and no conflicts of interest for this work.

\section{References}

1. Sung H, Ferlay J, Siegel RL, et al. Global Cancer Statistics 2020: GLOBOCAN estimates of incidence and mortality worldwide for 36 cancers in 185 countries. CA Cancer J Clin. 2021;71(3):209-249. doi:10.3322/caac.21660

2. Jackson-Thompson J, Ahmed F, German RR, Lai SM, Friedman C. Descriptive epidemiology of colorectal cancer in the United States, $1998-2001$. Cancer. 2006;107(S5):1103-1111. doi:10.1002/cner.22007

3. Compton CC, Grace FL. The staging of colorectal cancer: 2004 and beyond. CA Cancer J Clin. 2004;54(6):295-308. doi:10.3322/canjclin.54.6.295

4. Moolla Z, Madiba TE. Trends in demographics and management of obstructing colorectal cancer. World J Surg. 2014;38(9):2466-2470. doi:10.1007/s00268-014-2595-y

5. Folosade PM, Anandasabapathy S. Colon cancer in Africa: primetime for screening? Gastrointest Endosc. 2019;89(6):1238-1240.

6. Graham A, Davies Adeloye LG, Theodoratou E, Campbell H. Estimating the incidence of colorectal cancer in Sub-Saharan Africa: a systematic analysis. J Glob Health. 2012;2(2). doi:10.7189/jogh.02.020404

7. Parker RK, Mwachiro MM, Ranketi SS, Mogambi FC, Topazian HM, White RE. Curative surgery improves survival for colorectal cancer in rural Kenya. World J Surg. 2020;44(1):30-36. doi:10.1007/s00268-019-05234-1

8. Malvezzi M, Carioli G, Bertucci P, et al. European cancer mortality predictions for the year 2018 with focus on colorectal cancer. Ann Oncol. 2018;29(4):1016-1022. doi:10.1093/annonc/mdy033

9. Ginsberg GM, Lover JA, Zelle S, Beaten S, Baltussen R. Cost effectiveness of strategies to combat breast, cervical and colorectal cancer in Sub-Saharan Africa and South East Asia: mathematical modelling study. BMJ. 2012;344:614. doi:10.1136/bmj.e614

10. Agyemong-Yeboah F, Yorke J, Obirikorang C, et al. Colorectal survival rates in Ghana: a retrospective hospital-based study. PLoS One. 2018;13 (12):1-15.

11. Roncucci L, Fante R, Losi L, et al. Survival of colon and rectal cancer in a population-based cancer registry. Eur J Cancer. 1996;32(2):295-302. doi:10.1016/0959-8049(95)00532-3

12. Brand M, Gaylard P, Ramos J. Colorectal cancer in South Africa: an assessment of disease presentation, treatment pathways and 5-year survival. S Afr Med J. 2018;108(2):118-122. doi:10.7196/SAMJ.2018.v108i2.12338

13. Amin MB, Greene FL, Edge SB, et al. The Eighth Edition AJCC cancer staging manual: continuing to build a bridge from a population-based to a more "personalized" approach to cancer staging. CA Cancer J Clin. 2017;67(2):93-99. PMID: 28094848. doi:10.3322/caac.21388

14. Hamilton S, Bosman F, Boffetta P. Carcinoma of the colon and rectum. In: Bosman F, Carneiro F, Hruban R, Theise N, editors. World Health Organization Classification of Tumors of the Digestive System. Lyon: IARC Press; 2010:131-181. 
15. Turner J. Gastrointestinal Tract. In: Kumar V, Abbas A, Fausto N, Aster J, editors. Pathologic Basis of Disease. 8th ed. Philadelphia: Saunders Elsevier; 2010:822-825.

16. Faivre-Finn C, Bouvier-Benhamiche A, Philip J, Manfredi S, Dancourt V, Faivre J. Colon cancer in France: evidence for improvement in management and survival. Gut. 2002;51(1):60-64. doi:10.1136/gut.51.1.60

17. Saidi H, Abdihakin M, Njihia B, et al. Clinical outcomes of colorectal cancer in Kenya. Ann Afr Surg. 2011;7(1). doi:10.4314/aas.v7i1.67029

18. Atinafu BT, Bulti FA, Demelew TM. Survival status and predictors of mortality among colorectal cancer patients in Tikur Anbessa Specialised Hospital in Addis Ababa, Ethiopia: a retrospective follow-up study. J Cancer Prev. 2020;25(1):38-47. doi:10.15430/JCP.2020.25.1.38

19. Majano SB, Girolamo CD, Rachet B, et al. Surgical treatment and survival from colorectal cancer in Denmark, England, Norway and Sweden: a population-based study. Lancet Oncol. 2019;20(1):74-87. doi:10.1016/S1470-2045(18)30646-6

20. Lee CH, Cheng SC, Tung HY, Chang SC, Ching CY, Wu SF. The risk factors affecting survival in colorectal cancer in Taiwan. Iran J Public Health. 2018;47(4):519-530.

21. Magaji BA, Moy FM, Roslani AC, Law CW. Survival rates and predictors of survival among colorectal cancer patients in a Malaysian tertiary hospital. BMC Cancer. 2017;17(1):339. doi:10.1186/s12885-017-3336-Z

22. Rasouli MA, Morodi G, Roshani D, Nikkhoo B, Ghaderi E, Ghaytasi B. Prognostic factors and survival of colorectal cancer in Kurdistan province, Iran: a population-based study (2009-2014). Medicine. 2017;96(6):e5941. doi:10.1097/MD.0000000000005941

23. Sharkas GF, Arqoub KH, Khader YS, et al. Colorectal cancer in Jordan: survival rate and its related factors. J Oncol. 2017;2017:318076. doi:10.1155/2017/3180762

24. Sankaranarayanan R, Swaminathan R, Jayant K, Brenner H. An overview of cancer survival in Africa, Asia, the Caribbean and Central America: the cae for investment in cancer health services. IARC Sci Publ. 2011;162:257-291.

25. Anderson G. Non-communicable chronic diseases: winning on facts but losing on Passion. Health Syst Reform. 2015;1(2):119-127. doi:10.4161/ 23288604.2014.989753

26. Gharbi O, Chabchoub I, Limam S, et al. Prognostic factors and survival of metastatic colorectal cancer in the Sousse University Hospital (Tunisia): comparative study of two treatment periods of 200 patients. Bull Cancer. 2010;97(4):445-451. doi:10.1684/bdc.2010.1083

27. Moghimi-Dehkordi B, Saface A. An overview of colorectal cancer survival rates and prognosis in Asia. World J Gastrointest Oncol. 2012;4 (4):71-75. doi:10.4251/wjgo.v4.i4.71

28. Zhang S, Gao F, Luo J, Yang J. Prognostic factors in survival of colorectal cancer patients with synchronous liver metastasis. Colorectal Dis. 2010;12(8):754-761. doi:10.1111/j.1463-1318.2009.01911.x

29. Abu Hassan MR, Ismail I, Mohd Suan MA, et al. Incidence and mortality rates of colorectal cancer in Malaysia. Epidemiol Health. 2016;38: e2016007. doi:10.4178/epih.e2016007

30. Lieu CH, Renfro LA, de Gramont A, et al. Association of age with survival in patients with metastatic colorectal cancer: analysis from the arcad clinical trials programme. J Clin Oncol. 2014;32(27):3975. doi:10.1200/JCO.2013.54.9329

31. Patel SS, Nelson R, Sanchez J, et al. Elderly patients with colon cancer have unique tumour characteristics and poor survival. Cancer. 2013;119 (4):739. doi:10.1002/cncr.27753

32. Sudsawat L, Maneechavakajorn J, Techatonal P. Prognostic factors for survival in colorectal cancer patients. J Med Associat Thailand. 2010;93:1156.

33. Rosenberg R, Friederichs J, Schuster T, et al. Prognosis of patients with colorectal cancer is associated with lymph node ratio: a single-centre analysis of 3026 patients over a 25-year time period. Ann Surg. 2008;248(6):968-978. doi:10.1097/SLA.0b013e318190eddc

34. Mehrkhani F, Nasiri S, Donboli K, Meysami A, Hedeyat A. Prognostic factors in survival of colorectal cancer patients after surgery. Colorectal Dis. 2009;11(2):157. doi:10.1111/j.1463-1318.2008.01556.x

35. Cronje L, Paterson A, Becker P. Colorectal cancer in South Africa: a heritable cause suspected in many young black patients. S Afr Med J. 2009;99 (2):103-106.

36. Wentink MQ, Rakers M, Stupard DA, et al. Incidence and histological features of colorectal cancer in the Northern Cape Province of South Africa. S Afr J Surg. 2010;48(4):109-113.

37. Barrett J, Jiwa M, Rose P, Hamilton W. Pathways to the diagnosis of colorectal cancer: an observational study in three UK cities. Fam Pract. 2006;23(1):15-19. doi:10.1093/fampra/cmi093

38. Altekruse SF, Kosary CL, Krapeho M, et al. SEER Cancer Statistics Review, 1975-2007. Bethesda, MD: National Cancer Institute; 2010.

39. Saha A, Smith K, Sue-Ling H, Sagar P, Burke D, Finan P. Prognostic factors for survival after curative resection of Duke's B colonic cancer. Colorectal Dis. 2011;13(12):1390-1394. doi:10.1111/j.1463-1318.2010.02507.x

40. Moghimi-Dehkordi B, Safaee A, Zali MR. Prognostic factors in 1138 Iranian colorectal cancer patients. Int J Colorectal Dis. 2008;23(7):683-688. doi:10.1007/s00384-008-0463-7

41. Oberoi DV, Jiwa M, McManus A, Hodder R. Colorectal cancer-applying a gender lens. Qual Prim Care. 2014;22(2):71-79.

42. Al-Ahwal MS, Shafik YH, al-Ahwal HM. First national survival rate data for colorectal cancer among Saudis between 1994 and 2004: what's next? BMC Public Health. 2013;13(73):1471-2458. doi:10.1186/1471-2458-13-73

43. Bufalari A, Giustozzi G, Burattini MF, et al. Rectal cancer surgery in the elderly: a multivariate analysis of outcome risk factors. $J$ Surg Oncol. 2006;93(3):173-180. doi:10.1002/jso.20300

44. Radzi Abu-Hassan M, Azri Mohd Suan M, Aiman SS, Syahireen MN, Ismail I, Ahmad F. Survival analysis and prognostic factors for colorectal cancer patients in Malaysia. Asian Pac J Cancer Prev. 2016;17(7):3575-3581.

45. Kumar S, Burney IA, Zahid KF, et al. Colorectal cancer patient characteristics, treatment and survival in Oman- a single centre study. Asian Pac $J$ Cancer Prev. 2015;16(12):4853-4858. doi:10.7314/APJCP.2015.16.12.4853

46. Vaccaro CA, Im V, Rossi GL, et al. Lymph node ratio as prognosis factor for colon cancer treated by colorectal surgeons. Dis Colon Rectum. 2009;52(7):1244. doi:10.1007/DCR.0b013e3181a65fob

47. Kuipers EJ, Grady WM, Lieberman D, et al. Colorectal cancer. Nat Rev Dis Primers. 2015;1(1):15065. doi:10.1038/nrdp.2015.65

48. Lee YC, Lee YL, Chuang JP, Lee JC. Differences in survival between colon and rectal cancer from SEER data. PLoS One. 2013;8(11):e78709.

49. Wang Y, Yang L, Zhou M, et al. Disparities in survival for right-sided vs. left-sided colon cancers in young patients: a study based on surveillance, epidemiology and end results database (1990-2014). Cancer Manag Res. 2018;10:1735-1747. doi:10.2147/CMAR.S163302 
50. Warschkow R, Sulz MC, Marti L, et al. Better survival in right-sided versus left sided stage I-III colon cancer patients. BMC Cancer. 2016;16 (1):554. doi:10.1186/s12885-016-2412-0

51. Weiss JM, Pfau PR, O’Connor ES, et al. Mortality by stage for right versus left-sided colon cancer: analysis of surveillance, epidemiology and end results-Medicare data. J Clin Oncol. 2011;29(33):4401-4409. doi:10.1200/JCO.2011.36.4414

52. Meguid RA, Slidell MB, Wolfgang CL, Chang DC, Ahuja N. Is there a difference in survival between right versus left-sided colon cancers? Am Surg Oncol. 2008;15(9):2388-2394. doi:10.1245/s10434-008-0015-y

53. Jess P, Hansen IO, Gamborg M, et al.; Danish colorectal cancer group. A nationwide Danish cohort study challenging the categorization in to right-sided and left-sided colon cancer. BMJ Open. 2013;3:3e002608.

54. Hussain M, Waqas O, Hassan U, et al. Right sided and left sided colon cancers are two different distinct entities: an analysis of 200 cases in Pakistan. Asian Pac J Cancer Prev. 2016;17(5):2545-2548.

55. Lim DR, Kuk JK, Kim T, Shin EJ. Comparison of oncological outcomes of right-sided colon cancer versus left-sided colon cancer after curative resection. Which Side is Better Outcome?. Medicine. 2017;96(42):1-7.

56. Hansen IO, Jess P. Possible better long-term survival in left versus right-sided colon cancer: a systematic review. Dan Med J. 2012;59:4444.

57. Yahagi M, Okabayashi K, Hasegawa H, et al. The worse prognosis of right-sided compared with left-sided colon cancers: a systematic review and meta-analysis. J Gastrointest Surg. 2016;20:648-655.

58. Lee GH, Melietzis G, Askari A, et al. Is right-sided colon cancer different to left-sided colorectal cancer? A systematic review. Eur J Surg Oncol. 2015;41(3):300-308. doi:10.1016/j.ejso.2014.11.001

59. Petrelli F, Tomasello G, Borgonovo K, et al. Prognostic survival associated with left-sided versus right-sided colon cancer: a systematic review and meta-analysis. JAMA Oncol. 2016;27:4227.

60. Keskin M, Sivrikoz E, Yegen G, et al. Right versus left colon cancers have comparable survival: a decade's experience. Indian J Surg. 2020;82 (2):134-141. doi:10.1007/s12262-019-01900-9

61. Sullivan R, Alatise OI, Anderson BO, et al. Global cancer surgery: delivering safe, affordable, and timely cancer surgery. Lancet Oncol. 2015;16 (11):1193-1224. doi:10.1016/S1470-2045(15)00223-5

62. Shulman LN, Mpunga T, Tapela N, Wagner CM, Fadelu T, Binagwaho A. Bringing cancer care to the poor: experiences from Rwanda. Nat Rev Cancer. 2014;14(12):815. doi:10.1038/nrc3848

63. Zafar SN, Siddiqui AH, Channa R, Ahmed S, Javed AA, Bafford A. Estimating the global demand and delivery of cancer surgery. World J Surg. 2019;43(9):2203-2210. doi:10.1007/s00268-019-05035-6

64. Neal R, Tharmanathan P, France B, et al. Is increased time to diagnosis and treatment in symptomatic cancer associated with poorer outcomes? Systematic review. Br J Cancer. 2015;11(S1):S92. doi:10.1038/bjc.2015.48

65. StataCorp. Stata statistical software: release 14. College Station, TX:StataCorp LP; 2015.

66. Irabor D, Adedeji OA. Colorectal cancer in Nigeria: 40 years on. A review. Eur J Cancer Care. 2009;18(2):110-115. PMID: 19267725. doi:10.1111/j.1365-2354.2008.00982.x

67. Yamauchi M, Morikawa T, Kuchiba A, et al. Assessment of colorectal cancer molecular features along bowel subsites challenges the conception of distinct dichotomy of proximal versus distal colorectum. Gut. 2012;61(6):847-854. PMID: 22427238; PMCID: PMC3345105. doi:10.1136/gutjnl2011-300865

Cancer Management and Research

Dovepress

Publish your work in this journal

Cancer Management and Research is an international, peer-reviewed open access journal focusing on cancer research and the optimal use of preventative and integrated treatment interventions to achieve improved outcomes, enhanced survival and quality of life for the cancer patient. The manuscript management system is completely online and includes a very quick and fair peer-review system, which is all easy to use. Visit http://www.dovepress.com/testimonials.php to read real quotes from published authors.

Submit your manuscript here: https://www.dovepress.com/cancer-management-and-research-journal 